\title{
SPECIAL TOPIC \\ Identifying Windows of Opportunity for Active Living and Healthy Eating Policies in Connecticut, 2016
}

\author{
Anna E. Greer, PhD, $\mathrm{CHES}^{1}$; Ann Knausenberger, BS $^{2}$
}

\begin{abstract}
Accessible Version: www.cdc.gov/pcd/issues/2018/17_0331.htm
Suggested citation for this article: Greer AE, Knausenberger A. Identifying Windows of Opportunity for Active Living and Healthy Eating Policies in Connecticut, 2016. Prev Chronic Dis 2018;15:170331. DOI: https://doi.org/10.5888/pcd15.170331.
\end{abstract}

\section{PEER REVIEWED}

\section{Abstract}

We examined the relative importance of 23 community issues among elected officials and health directors in Connecticut in 2016. For this cross-sectional study, 74 elected officials ( $40.7 \%$ response rate) and 47 health directors (62.7\% response rate), who were purposively sampled, completed a questionnaire to rate their perceived importance of 23 community issues. Eight of these issues were related to active living, healthy eating, or obesity. We used $\chi^{2}$ tests to evaluate differences in responses. Compared with elected officials, health directors significantly more often perceived obesity, access to healthy groceries, poor nutrition, lack of pedestrian walkways, and pedestrian safety as important. Elected officials significantly more often than health directors perceived lack of good jobs, quality of public education, and cost of living as important. Health advocates should work with both groups to develop and frame policies to address both upstream (eg, jobs, education) and downstream (eg, healthy eating policies) determinants of obesity.

\section{Background}

More than one-third (36.5\%) of Americans are obese (1). Active living and healthy eating are associated with a reduced risk of obesity (2). Unhealthy diets and physical inactivity, however, are a problem in the United States $(3,4)$.

State legislatures can create policies to support healthy eating and active living. For example, Kansas addressed healthy food access with policies to support farmers markets, including restrictions on liability and city fees (5). Massachusetts passed legislation that provides financial incentives to communities that pass high-density zoning regulations to support walkable, urban centers (6).

State policies require support from elected officials and other key stakeholders. Little research has examined the relative importance of healthy eating and active living issues at the state level. One study surveyed elected officials in Hawaii on the perceived importance of 23 community issues (7). Six of the issues were related to active living, but only an increase in vehicular traffic was recognized as relatively important. A follow-up study examined elected official's perceptions of the same issues from 2007 to 2013 (8). The perceived importance of obesity increased over time, while perceived importance of increasing vehicular traffic, poorly planned development, and pedestrian safety declined.

Another study examined the perceived importance of active living, healthy eating, and obesity among legislators in Kansas (9). Obesity was rated second highest, after jobs. Healthy eating and active living issues were not deemed important. These findings suggest legislators might be unaware of how active living and healthy eating policies support obesity prevention.

Our study is the first peer-reviewed study to examine the relative importance of active living and healthy eating issues among elected state officials and municipal health directors. The findings highlight issues for which political support exists and ideas for how advocates of healthy eating and active living policies might better frame these issues (10). Identifying those issues is a crucial step in the policy development process (10). Previous research shows that advocating for healthy eating and active living policies can result in policy change in these areas (11).

\section{Study context}

Connecticut is a relatively small state with a population of approximately 3.6 million residents. The median household income is $\$ 70,331$, ranging from $\$ 29,313$ in Hartford to $\$ 208,078$ in West- 
on (12); the median household income in the United States is $\$ 53,889$ (13). The percentage of residents reporting white race is $81 \%$ but ranges from $28 \%$ in Hartford to $96 \%$ in Litchfield (14); in the United States, $77 \%$ of the population self-reports white race (13).

One-fourth (26.0\%) of Connecticut residents are obese. Racial/ethnic disparities exist in the prevalence of obesity: $37.7 \%$ of the black population, $30.3 \%$ of the Hispanic population, and $24.3 \%$ of the white population are obese (15). Overall, $21.8 \%$ of Connecticut residents meet national physical activity recommendations; in the United States, 20.1\% meet these recommendations (3). In Connecticut, $32.0 \%$ of adults consume fruits and $26.0 \%$ consume vegetables fewer than 1 time daily; these percentages are $37.7 \%$ and $22.6 \%$, respectively, in the United States (4).

Data on the distribution of political ideology among Connecticut officials are not available. To estimate this distribution, we weighted national-level data about Democratic and Republican political ideologies in 2016 (16) by the proportion of Democrats and Republicans in the Connecticut state legislature in 2016 (17). Using this formula, we estimated that $37.1 \%$ of elected officials in Connecticut were socially liberal, $27.6 \%$ socially moderate, and $33.8 \%$ socially conservative; $25.4 \%$ were fiscally liberal, $31.1 \%$ fiscally moderate, and $43.1 \%$ fiscally conservative in 2016 .

\section{Gathering and Analyzing Data}

We surveyed all elected officials at the state level (ie, senators and representatives) and all health directors at the municipal level in Connecticut. We used a census approach, whereby every person in the identified population was selected. In Connecticut, local health agencies are under the jurisdiction of the municipality they serve rather than the state commissioner (18). A list of all elected officials and health directors was available on the respective websites of the Connecticut General Assembly (19) and the Connecticut Department of Health (20). This led to a study population of 182 elected officials and 75 health directors. Survey participants were recruited via postal and electronic mail. Forty-seven health directors (62.7\% response rate) and 74 elected officials $(40.7 \%$ response rate) completed the study questionnaire from January through November 2016 for a total of 121 respondents.

Study materials sent via postal mail included a cover letter, an informed consent form, a study questionnaire, and a self-addressed postage-paid envelope. Study materials sent via electronic mail included a cover letter, an informed consent form, and a web link that directed respondents to SurveyMonkey to complete the questionnaire. All participants provided informed consent before participating in the study. All respondents were sent 2 follow-up reminders via electronic and postal mail. No incentives were offered. The study was framed as an opportunity for advocates to understand the community priorities of elected officials and health directors. The Sacred Heart University Institutional Review Board approved all study procedures.

For the questionnaire, we used a survey developed for a study examining policy makers' perceptions of community issues in Hawaii (7). The questionnaire invited respondents to rate the importance of 23 issues in Connecticut (Table 1) on a 5-point Likert scale (1, not a problem at all; 3, may or may not be a problem; 5, problem of extreme importance). These items were recoded for analysis into important (score of 1 or 2) or not important (score of 3,4 , or 5). A response of 3 was grouped with a response of 4 and 5 because respondents who perceive that an issue "may or may not be a problem" would be unlikely to act to support policies for that issue. Because our study focused on identifying opportunities for policy change, we used potential for policy action as the guide for creating categories. Respondents were asked to indicate their political ideology for social issues and fiscal issues (conservative, moderate, liberal), and beliefs that government restrictions and tax increases should be used to protect health (never/rarely, sometimes, often/always) (Table 2).

All data were loaded into SPSS version 24.0 (IBM Corp) for analysis. We used descriptive statistics to describe the data and $\chi^{2}$ tests to examine associations between 1) respondent type (elected official or health director) and perceived importance of community issues (yes or no), 2) respondent type and political ideology, 3) political ideology and perceived importance of community issues (yes or no). We ran $\chi^{2}$ goodness-of-fit tests to determine whether the distribution of elected officials who were socially and fiscally liberal, moderate, and conservative generated by our estimates was different from the distribution among elected officials who responded to our survey. We were unable to run a similar analysis for health directors because we could not find data on the political ideologies of health directors in Connecticut. Statistical significance was set at $P<.05$ for all tests.

\section{Findings}

We found no significant difference between the distribution of social ideology of elected officials who participated in our study and our estimated distribution of elected officials in the Connecticut state legislature in $2016\left(\chi_{2}^{2}=4.7, P=.10\right)$. However, the proportion of fiscally liberal elected officials in our study $(35.7 \%)$ was greater than the estimated proportion $(20.9 \%)\left(\chi_{2}^{2}=10.1, P=\right.$ $.007)$. A larger proportion of elected officials (35.7\%) than health directors $(6.5 \%)$ reported being fiscally liberal $\left(\chi_{2}^{2}=17.0, P<\right.$ .001 ) (Table 2). Health directors more often than elected officials

The opinions expressed by authors contributing to this journal do not necessarily reflect the opinions of the U.S. Department of Health and Human Services, the Public Health Service, the Centers for Disease Control and Prevention, or the authors' affiliated institutions. 
supported using government restrictions $\left(\chi_{2}^{2}=8.3, P=.02\right)$ and tax increases $\left(\chi_{2}^{2}=12.2, P=.002\right)$ to protect the public's health.

Nine issues were deemed important by at least half of both elected officials and health directors (Table 1). The 3 issues of greatest importance to both groups were drug abuse, lack of jobs, and cost of living. Among the obesity-related issues, only obesity, poorly planned development/sprawl, and increasing traffic were identified as important by at least half of both groups.

A significantly greater proportion of health directors than elected officials deemed obesity, access to healthy groceries, poor nutrition, lack of pedestrian walkways, pedestrian safety, crime, pandemic influenza, drug abuse, tobacco, and access to health care as important. A significantly greater proportion of elected officials than health directors deemed quality of public education, lack of good jobs, and cost of living as important.

A significantly greater proportion of fiscally liberal than fiscally conservative respondents perceived climate change, quality of public education, poorly planned development/sprawl, access to health care, poverty, pedestrian safety, lack of affordable housing, access to healthy groceries, poor nutrition, and homelessness as important (Table 3). On the other hand, a significantly greater proportion of fiscally conservative respondents than fiscally liberal respondents perceived high taxes as important.

A significantly greater proportion of socially liberal respondents than socially conservative respondents perceived climate change, quality of public education, poorly planned development/sprawl, access to health care, poverty, pedestrian safety, access to healthy groceries, and poor nutrition as important. Compared with socially liberal respondents, socially conservative respondents more often perceived high taxes as important.

\section{Opportunities for Application of Findings}

Elected officials and fiscally conservative respondents were less supportive of tax increases to protect health and more concerned about high taxes than health directors and fiscally liberal respondents. The elected officials in our study were more fiscally liberal than the body of all elected officials in Connecticut, indicating that support for tax increases to protect health is likely even lower in Connecticut than estimated by our study. Our findings suggest that health advocates will likely find resistance when advocating for policies that require a large amount of funding for policy implementation. An alternative to an increase in taxes is a collaboration of community partners that contribute funds. For example, the Pennsylvania Fresh Food Financing Initiative was a public-private partnership that supported access to healthy food in that state (21).
Pennsylvania provided a $\$ 30$ million grant and the Reinvestment Fund contributed $\$ 145$ million; these funds were used to provide loans to attract grocery stores to communities in need of access to healthy food (22).

Our findings also indicate that socially and fiscally liberal respondents perceived active living and healthy eating issues as more important than did socially and fiscally conservative respondents. Advocates must reframe their arguments for active living and healthy eating policies to identify how these policies can support personal and public cost savings. For example, a tax on sugar-sweetened beverages could reduce soda consumption while raising revenue for states (23).

Obesity was identified as important by at least half of both elected officials and health directors. Policies, however, cannot be developed to ban or reduce obesity. Rather, policies that support active living and healthy eating can enable people to achieve a healthy weight. For example, North Carolina designated funds to develop a light rail system in Charlotte; use of this system was associated with a reduction in the odds of residents becoming obese (24). Previous studies identified limited awareness among elected officials about the connection between obesity and active living and healthy eating policies $(7,9)$. Health advocates might share information on resources such as the State Legislative and Regulatory Action to Prevent Obesity and Improve Nutrition and Physical Activity (25) with elected officials and health directors, so that people who are developing policy have clear examples from which to work.

Elected officials in our study were more concerned than health directors with public education, lack of good jobs, and cost of living. Social determinants, or conditions in which people are born and live, likely contribute most to the growing prevalence of obesity (2). Opportunities exist for elected officials and health directors to work together to develop policies that address issues of concern for both groups: upstream social determinants and downstream active living and healthy eating initiatives. For example, in Bridgeport, Connecticut, a zoning regulation was changed to allow food entrepreneurs to prepare healthy food products in church kitchens before selling them locally at farmers markets (26). Before this change, food production could occur only in more expensive commercial kitchens, limiting opportunities for healthy food production and sale by lower-income residents. Policies like this at the state level have the potential to affect both job opportunities and access to healthy food.

The only active living issues deemed as important by at least half of both elected officials and health directors were increasing traffic and poorly planned development/sprawl. A study in 2007 identified increasing traffic as important among Hawaii elected of-

The opinions expressed by authors contributing to this journal do not necessarily reflect the opinions of the U.S. Department of Health and Human Services, the Public Health Service, the Centers for Disease Control and Prevention, or the authors' affiliated institutions. 
ficials (7), but by 2013 the importance of increasing traffic had declined (8). Policies to reduce traffic and poorly planned development/sprawl should be pursued immediately in Connecticut because support exists from both elected officials and health directors at this time. The presence of sidewalks, an issue of importance to health directors, or increased funding for public transportation could support active transportation $(27,28)$ and reduce traffic $(29)$.

The 3 issues of greatest importance to both groups were drug abuse, lack of good jobs, and cost of living. These are vital issues in Connecticut (30,31). The proportion of persons with past-year illicit drug abuse was higher in Connecticut $(2.9 \%)$ than in the United States (2.6\%) (30). The cost of living in Connecticut is $29 \%$ higher than it is for the average US household (31). The proportion of persons in the Connecticut labor force $(67.2 \%)$ is higher than the national average (63.3\%) (32). However, employment is an important determinant of well-being (2), supporting Connecticut leaders' concern for job opportunities.

Our findings indicate that windows of opportunity currently do not exist for healthy eating policies unless they are linked to obesity or other areas of alignment. A study in 2013 (9) found that elected officials in Kansas did not view healthy eating issues as relatively important. Because health directors in our study more often than elected officials perceived poor nutrition and access to healthy groceries as important, health directors should work with elected officials to communicate information on the links between healthy eating policies and obesity prevention.

\section{Additional Considerations}

Our study has several limitations. The study is cross-sectional and therefore does not allow causal inferences. Questionnaire responses were self-reported, so they could have been affected by social desirability bias. Our findings have limited generalizability and could differ in a subsequent election cycle. The issues addressed in the questionnaire ranged in specificity. For example, education could influence myriad outcomes. Too few sidewalks, on the other hand, is a specific barrier to promoting active living. Our study is strengthened by the inclusion of a questionnaire used in 3 previous studies (7-9), which allowed for comparisons across studies and states. In addition, our analyses of how the political ideologies of elected officials in our study align with all Connecticut elected officials allow readers to better determine generalizability.

Our findings indicate that active living and healthy eating issues are priority areas for health directors but that elected officials are more concerned with social determinants of health. Health advocates should work with health directors and elected officials to develop policies that address both upstream social determinants (eg, jobs, education) and downstream behavioral supports (eg, physical activity and healthy eating policies) that act as determinants of obesity. Health advocates will have more success if proposed policies do not increase taxes.

\section{Acknowledgments}

This study was supported by a University Creativity and Research Grant from Sacred Heart University.

\section{Author Information}

Corresponding Author: Anna E. Greer, PhD, CHES, Associate Professor, Department of Public Health, Sacred Heart University, 5151 Park Ave, Fairfield, CT 06825. Telephone: 203-416-3936. E-mail: greera@sacredheart.edu.

Author Affiliations: ${ }^{1}$ Department of Public Health, Sacred Heart University, Fairfield, Connecticut. ${ }^{2}$ Department of Physical Therapy and Human Movement Science, Sacred Heart University, Fairfield, Connecticut.

\section{References}

1. Ogden C, Carroll M, Fryar C, Flegal K. Prevalence of obesity among adults and youth: United States, 2011-2014. Hyattsville (MD): National Center for Health Statistics; 2015.

2. Institute of Medicine. Accelerating progress in obesity prevention: solving the weight of the nation. Washington (DC): National Academies Press; 2012.

3. Centers for Disease Control and Prevention. State indicator report on physical activity, 2014. Atlanta (GA): US Department of Health and Human Services; 2014.

4. National Center for Chronic Disease Prevention and Health Promotion. State indicator report on fruits and vegetables, 2013. Atlanta (GA): Centers for Disease Control and Prevention, US Department of Health and Human Services; 2013.

5. Public Health Law Center at William Mitchell College of Law. State laws impacting farmers' markets in Kansas 2014. http:// www.publichealthlawcenter.org/sites/default/files/resources/ 08\%2018\%2014\%20State\%20Laws\%20Impacting\%20Farmer s\%20Markets\%20in\%20Kansas.pdf. Accessed October 9, 2017.

6. Concord Square Planning \& Development Inc (CSPD). Smart growth zoning: Massachusetts general laws chapter 40R. http:// www.concordsqdev.com/smart-growth-zoning/. Accessed October 9, 2017.

\footnotetext{
The opinions expressed by authors contributing to this journal do not necessarily reflect the opinions of the U.S. Department of Health and Human Services, the Public Health Service, the Centers for Disease Control and Prevention, or the authors' affiliated institutions.
} 
7. Maddock JE, Reger-Nash B, Heinrich K, Leyden KM, Bias TK. Priority of activity-friendly community issues among key decision makers in Hawaii. J Phys Act Health 2009; 6(3):386-90.

8. McGurk M, Maddock J. Changes in policy maker attitudes towards active living communities issues in Hawaii, 2007-2013. J Phys Act Health 2016;13(10):1056-62.

9. Heinrich KM, Stephen MO, Vaughan KB, Kellogg M. Kansas legislators prioritize obesity but overlook nutrition and physical activity issues. J Public Health Manag Pract 2013; 19(2):139-45.

10. Kingdon J. Agendas, alternatives, and public policies. 2nd ed. Chicago (IL): Pearson Education, Inc; 2011.

11. Samuels SE, Craypo L, Boyle M, Crawford PB, Yancey A, Flores G. The California Endowment's healthy eating, active communities program: a midpoint review. Am J Public Health 2010;100(11):2114-23.

12. State of Connecticut Department of Economic and Community Development. American Community Survey, 2014. http:// www.ct.gov/ecd/cwp/view.asp? $a=1106 \& q=250652$. Accessed October 9, 2017.

13. National Center for Chronic Disease Prevention and Health Promotion, Division of Nutrition and Physical Activity, and Obesity. State indicator report on fruits and vegetables. 2013. https://www.cdc.gov/nutrition/downloads/state-indicatorreport-fruits-vegetables-2013.pdf.

14. US Census Bureau. Census Viewer, 2010. http:// censusviewer.com/cities/CT. Accessed October 9, 2017.

15. Trust for America's Health, Robert Wood Johnson Foundation. The state of obesity in Connecticut, 2017. https:// stateofobesity.org/states/ct. Accessed October 8, 2017.

16. Jones J. Democrats more liberal on social issues than economic ones 2016. http://www.gallup.com/poll/191741/democratsliberal-s ocial-issues-economic-ones aspx? g source $=$ social + ideology \&g_medium $=$ search\&g_ campaign=tiles. Accessed August 14, 2017.

17. Pazniolas M.A quick guide to the 2016 CT General Assembly. The CT Mirror. 2016February 3. https:/ctmirror.org/2016/02/ 03/a-quick-guide-to-the-2016-connecticut-general-assembly/. October 9, 2017.

18. Connecticut Department of Public Health. The Connecticut Department of Public Health office of local health administration and local health infrastructure overview, 2017. http://www.ct.gov/dph/cwp/view.asp?a=3123\&Q=388754. Accessed October 8, 2017.

19. Connecticut General Assembly. Connecticut General Assembly: representation 2017. https://www.cga.ct.gov/. Accessed October 8, 2017.
20. Connecticut Department of Public Health. Connecticut local health, 2017 . http://www.ct.gov/d ph/cwp/ view.asp? $\mathrm{a}=3123 \& \mathrm{q}=397740$. Accessed October 8, 2017.

21. Policy Link, The Food Trust, The Reinvestment Fund. A healthy food financing initiative: an innovative approach to improve health and spark economic development fact sheet 2012. http://www.frbsf.org/community-development/files/ healthy_food_financing_initiative.pdf. Accessed October 9, 2017.

22. Reinvestment Fund. Pennsylvania fresh food financing initiative 2017. https://www.reinvestment.com/success-story/ pennsylvania-fresh-food-financing-initiative/. Accessed October 8, 2017.

23. Brownell KD, Frieden TR. Ounces of prevention - the public policy case for taxes on sugared beverages. N Engl J Med 2009;360(18):1805-8.

24. MacDonald JM, Stokes RJ, Cohen DA, Kofner A, Ridgeway GK. The effect of light rail transit on body mass index and physical activity. Am J Prev Med 2010;39(2):105-12.

25. National Center for Chronic Disease Prevention and Health Promotion. State legislative and regulatory action to prevent obesity and improve nutrition and physical activity, 2015. https://www.cdc.gov/nchs/pressroom/states/CT_2015.pdf. Accessed October 9, 2017.

26. Lockhart B.Bridgeport's church kitchens hold commercial promise. CT Post. 2016 June 20, 2016. http://www.ctpost.com/ local/article/Bridgeport-s-church-kitchens-hold-commercial8310982.php. Accessed October 9, 2017.

27. Sallis JF, Frank DL, Saelens BE, Kraft MK. Active transportation and physical activity: opportunities for collaboration on transportation and public health research. Transp Res Part A Policy Pract 2004;38(4):249-68.

28. McCormack GR, Shiell A. In search of causality: a systematic review of the relationship between the built environment and physical activity among adults. Int J Behav Nutr Phys Act 2011;8:125.

29. Ewing R, Greenwald M, Zhang M, Walters J, Feldman M, Cervero R, et al. Traffic generated by mixed-use developments - six-region study using consistent build environment measures. J Urban Plann Dev 2011;137(3):248-61.

30. Substance Abuse and Mental Health Services Association. Behavioral health barometer: Connecticut, 2015. Rockville (MD): Substance Abuse and Mental Health Services Association; 2015.

31. Missouri Economic Research and Information Center. Cost of living data series 2017. https://www.missourieconomy.org/ indicators/cost of living/. Accessed August 11, 2017.

The opinions expressed by authors contributing to this journal do not necessarily reflect the opinions of the U.S. Department of Health and Human Services, the Public Health Service, the Centers for Disease Control and Prevention, or the authors' affiliated institutions. 
32. US Census Bureau. Quick facts - Connecticut, United States, 2016. https://www.census.gov/quickfacts/fact/table/CT,US/

PST045216. Accessed August 11, 2017.

The opinions expressed by authors contributing to this journal do not necessarily reflect the opinions of the U.S. Department of Health and Human Services, the Public Health Service, the Centers for Disease Control and Prevention, or the authors' affiliated institutions. 


\section{Tables}

Table 1. Community Issues Deemed Important, Overall and by Respondent Type, Connecticut, $2016^{\mathrm{a}}$

\begin{tabular}{|c|c|c|c|c|}
\hline \multirow[b]{2}{*}{ Community Issue } & \multirow{2}{*}{$\begin{array}{l}\text { All, No. (\%) } \\
(n=121)^{6}\end{array}$} & \multicolumn{2}{|c|}{ Respondent Type, No. (\%) } & \multirow[b]{2}{*}{$\mathrm{X}_{1}^{2}(P$ Value $)$} \\
\hline & & Elected Official $(n=74)^{b}$ & Health Director $(n=47)^{b}$ & \\
\hline \multicolumn{5}{|l|}{ Obesity-related issues } \\
\hline Obesity & $89(74.2)$ & $44(59.5)$ & $45(97.8)$ & $21.8(<.001)$ \\
\hline Increasing traffic & $85(71.4)$ & $53(72.6)$ & $32(69.6)$ & $0.1(.72)$ \\
\hline Poorly planned development/sprawl & $61(50.4)$ & $41(55.4)$ & $20(42.6)$ & $1.9(.17)$ \\
\hline Poor nutrition & $56(48.3)$ & $28(40.0)$ & $28(60.9)$ & $4.8(.03)$ \\
\hline Access to healthy groceries & $55(45.5)$ & $27(36.5)$ & $28(59.6)$ & $6.2(.01)$ \\
\hline Pedestrian safety & $42(35.9)$ & $18(25.7)$ & $24(51.1)$ & $7.9(.005)$ \\
\hline Lack of pedestrian walkways & $42(35.6)$ & $19(26.8)$ & $23(48.9)$ & $6.1(.01)$ \\
\hline Lack of recreational activities & $24(19.8)$ & $13(17.6)$ & $11(23.4)$ & $0.6(.41)$ \\
\hline \multicolumn{5}{|l|}{ Other health issues } \\
\hline Drug abuse & $114(94.2)$ & $67(90.5)$ & $47(100.0)$ & $4.7(.03)$ \\
\hline Access to health care & $62(51.2)$ & $32(43.2)$ & $30(63.8)$ & $4.9(.03)$ \\
\hline Climate change & $59(50.0)$ & $32(44.4)$ & $27(58.7)$ & $2.3(.13)$ \\
\hline Tobacco & $54(46.2)$ & $21(13.6)$ & $33(21.4)$ & $24.5(<.001)$ \\
\hline Pandemic influenza & $41(35.7)$ & $8(11.8)$ & $33(70.2)$ & $41.4(<.001)$ \\
\hline \multicolumn{5}{|l|}{ Social issues } \\
\hline Crime & $72(61.5)$ & $37(52.9)$ & $35(74.5)$ & $5.5(.02)$ \\
\hline Quality of public education & $66(55.5)$ & $49(68.1)$ & $17(36.2)$ & $11.7(.001)$ \\
\hline Homelessness & $62(53.0)$ & $40(57.1)$ & $22(46.8)$ & $1.2(.27)$ \\
\hline \multicolumn{5}{|l|}{ Economic issues } \\
\hline Lack of good jobs & $100(82.6)$ & $69(93.2)$ & $31(66.0)$ & $14.9(<.001)$ \\
\hline High taxes & $95(78.5)$ & $56(75.7)$ & $39(83.0)$ & $0.9(.34)$ \\
\hline Poverty & $91(75.8)$ & $54(74.0)$ & $37(78.7)$ & $0.4(.55)$ \\
\hline Cost of living & $86(73.5)$ & $57(81.4)$ & $29(61.7)$ & $5.6(.02)$ \\
\hline Lack of affordable housing & $83(69.2)$ & $55(75.3)$ & $28(59.6)$ & $11.7(.07)$ \\
\hline \multicolumn{5}{|l|}{ Government issues } \\
\hline Ethics in government & $70(57.9)$ & $46(62.2)$ & $24(51.1)$ & $1.5(.22)$ \\
\hline Government response to natural disasters & $24(20.5)$ & $12(17.1)$ & $12(25.5)$ & $1.2(.27)$ \\
\hline
\end{tabular}

${ }^{\text {a }}$ We surveyed all elected officials at the state level (ie, senators and representatives) and all health directors at the municipal level in Connecticut. Response rates were $40.7 \%$ ( 74 of 182) among state elected officials and $62.7 \%$ ( 47 of 75 ) among municipal health directors.

${ }^{\mathrm{b}}$ Not all respondents answered all questions. Percentages are based on the number of respondents who answered question. 
Table 2. Self-Reported Political Ideology and Beliefs, ${ }^{a}$ Overall and by Type of Respondent, Connecticut, $2016^{\text {b }}$

\begin{tabular}{|c|c|c|c|c|}
\hline \multirow[b]{2}{*}{ Political Ideology } & \multirow[b]{2}{*}{ All, No. $(\%)(n=121)^{c}$} & \multicolumn{2}{|c|}{ Respondent Type, No. (\%) } & \multirow[b]{2}{*}{$\mathrm{X}_{2}^{2}(P$ Value $)$} \\
\hline & & Elected Official $(n=74)^{c}$ & Health Director $(n=47)^{c}$ & \\
\hline \multicolumn{5}{|l|}{ Social issues } \\
\hline Liberal & $48(41.4)$ & $34(48.6)$ & $14(30.4)$ & \multirow[t]{3}{*}{$3.9(.14)$} \\
\hline Moderate & $39(33.6)$ & $20(28.6)$ & $19(41.3)$ & \\
\hline Conservative & $29(25.0)$ & $16(22.9)$ & $13(28.3)$ & \\
\hline \multicolumn{5}{|l|}{ Fiscal issues } \\
\hline Liberal & $28(24.1)$ & $25(35.7)$ & $3(6.5)$ & \multirow[t]{3}{*}{$17.0(<.001)$} \\
\hline Moderate & $28(24.1)$ & $10(14.3)$ & $18(39.1)$ & \\
\hline Conservative & $60(51.7)$ & $35(50.0)$ & $25(54.3)$ & \\
\hline \multicolumn{5}{|c|}{ Government restrictions should be used to protect health } \\
\hline Never/rarely & $31(27.0)$ & $25(36.2)$ & $6(13.0)$ & \multirow[t]{3}{*}{$8.3(.02)$} \\
\hline Sometimes & $66(57.4)$ & $33(47.8)$ & $33(71.7)$ & \\
\hline Often/always & $18(15.7)$ & $11(15.9)$ & $7(15.2)$ & \\
\hline \multicolumn{5}{|c|}{ Government tax increases should be used to protect health } \\
\hline Never/rarely & $45(38.5)$ & $35(50.0)$ & $10(21.3)$ & \multirow[t]{3}{*}{$12.2(.002)$} \\
\hline Sometimes & $55(47.0)$ & $24(34.3)$ & $31(66.0)$ & \\
\hline Often/always & $17(14.5)$ & $11(15.7)$ & $6(12.8)$ & \\
\hline
\end{tabular}

${ }^{a}$ Respondents were asked to indicate their political ideology for social issues and fiscal issues (conservative, moderate, liberal) and beliefs (never/rarely, sometimes, often/always) that government restrictions and tax increases should be used to protect health.

${ }^{\mathrm{b}}$ We surveyed all elected officials at the state level (ie, senators and representatives) and all health directors at the municipal level in Connecticut. Response rates were $40.7 \%$ (74 of 182) among state elected officials and $62.7 \%$ (47 of 75 ) among municipal health directors.

${ }^{\mathrm{C}}$ Not all categories add to column head because some respondents did not answer all questions. Percentages are based on the number of respondents who answered question. Column percentages in each category may not add to 100 because of rounding.

The opinions expressed by authors contributing to this journal do not necessarily reflect the opinions of the U.S. Department of Health and Human Services, the Public Health Service, the Centers for Disease Control and Prevention, or the authors' affiliated institutions. 
Table 3. Community Issues Deemed Important Among Elected Officials $(n=74)$ and Health Directors $(n=47)$, by Self-Reported Political Ideology ${ }^{a}$, Connecticut, $2016^{\mathrm{b}}$

\begin{tabular}{|c|c|c|c|c|}
\hline \multirow[b]{2}{*}{ Community Issue } & \multicolumn{3}{|c|}{ No. $(\%)^{c}$} & \multirow[b]{2}{*}{$\mathrm{X}_{2}^{2}(P$ Value $)$} \\
\hline & Liberal & Moderate & Conservative & \\
\hline \multicolumn{5}{|c|}{ Social Ideology ${ }^{d}$} \\
\hline \multicolumn{5}{|l|}{ Obesity-related issues } \\
\hline Obesity & $35(41.7)$ & $27(32.1)$ & $22(26.2)$ & $0.2(.91)$ \\
\hline Increasing traffic & $32(40.0)$ & $26(32.5)$ & $22(27.5))$ & $0.7(.69)$ \\
\hline Poorly planned development/sprawl & $30(52.6)$ & $19(33.3)$ & $8(14.0)$ & $8.8(.01)$ \\
\hline Poor nutrition & $30(54.5)$ & $17(30.9)$ & $8(14.5)$ & $8.6(.01)$ \\
\hline Access to healthy groceries & $29(56.9)$ & $15(29.4)$ & $7(13.7)$ & $10.4(.006)$ \\
\hline Pedestrian safety & $19(46.3)$ & $10(24.4)$ & $12(29.3)$ & $2.4(.29)$ \\
\hline Lack of pedestrian walkways & $24(58.5)$ & $10(24.4)$ & $7(17.1)$ & $7.1(.03)$ \\
\hline Lack of recreational activities & $11(52.4)$ & $6(28.6)$ & $4(19.0)$ & $1.3(.52)$ \\
\hline \multicolumn{5}{|l|}{ Other health issues } \\
\hline Drug abuse & $45(41.3)$ & $36(33.0)$ & $28(25.7)$ & $0.5(.76)$ \\
\hline Access to health care & $31(54.4)$ & $16(28.1)$ & $10(17.5)$ & $8.1(.02)$ \\
\hline Climate change & $30(53.6)$ & 19 (33.9) & $7(12.5)$ & $11.3(.004)$ \\
\hline Tobacco & $26(49.1)$ & $18(34.0)$ & $9(17.0)$ & $3.9(.14)$ \\
\hline Pandemic influenza & $13(32.5)$ & $14(35.0)$ & $13(32.5)$ & $2.4(.30)$ \\
\hline \multicolumn{5}{|l|}{ Social issues } \\
\hline Crime & $27(38.0)$ & $25(35.2)$ & $19(26.8)$ & $0.9(.65)$ \\
\hline Quality of public education & $32(52.5)$ & $17(27.9)$ & $12(19.7)$ & $6.8(.03)$ \\
\hline Homelessness & $31(50.8)$ & $18(29.5)$ & $12(19.7)$ & $4.9(.09)$ \\
\hline \multicolumn{5}{|l|}{ Economic issues } \\
\hline Lack of good jobs & $44(46.3)$ & $30(31.6)$ & $21(22.1)$ & $5.5(.06)$ \\
\hline High taxes & 33 (35.9) & $32(34.8)$ & $27(29.3)$ & $6.8(.03)$ \\
\hline Poverty & $42(48.8)$ & $25(29.1)$ & $10(22.1)$ & $7.1(.03)$ \\
\hline Cost of living & $34(40.0)$ & $31(36.5)$ & $20(23.5)$ & $1.2(.55)$ \\
\hline Lack of affordable housing & $38(48.1)$ & $22(27.8)$ & $19(24.1)$ & $5.2(.07)$ \\
\hline \multicolumn{5}{|l|}{ Government issues } \\
\hline Ethics in government & $26(38.8)$ & $26(38.8)$ & $15(22.4)$ & $2.0(.38)$ \\
\hline Government response to natural disasters & $11(47.8)$ & $9(39.1)$ & $3(13.0)$ & $2.2(.34)$ \\
\hline
\end{tabular}

${ }^{a}$ Respondents were asked to indicate their political ideology for social issues and fiscal issues (conservative, moderate, liberal).

${ }^{\mathrm{b}}$ We surveyed all elected officials at the state level (ie, senators and representatives) and all health directors at the municipal level in Connecticut. Response rates were $40.7 \%$ (74 of 182) among state elected officials and $62.7 \%$ ( 47 of 75 ) among municipal health directors.

${ }^{c}$ Not all respondents answered all questions. Percentages are based on the number of respondents who answered question. Row percentages may not add to 100 because of rounding.

${ }^{d}$ For social ideology among elected officials and health directors who answered question $(n=116), 29$ self-reported as liberal, 39 as moderate, and 48 as conservative.

${ }^{\mathrm{e}}$ For fiscal ideology among elected officials and health directors who answered question $(n=116), 60$ self-reported as liberal, 28 as moderate, and 28 as conservative. 
(continued)

Table 3. Community Issues Deemed Important Among Elected Officials $(n=74)$ and Health Directors $(n=47)$, by Self-Reported Political Ideology ${ }^{a}$, Connecticut, $2016^{\mathrm{b}}$

\begin{tabular}{|c|c|c|c|c|}
\hline \multirow[b]{2}{*}{ Community Issue } & \multicolumn{3}{|c|}{ No. $(\%)^{c}$} & \multirow[b]{2}{*}{$\mathrm{X}_{2}^{2}(P$ Value $)$} \\
\hline & Liberal & Moderate & Conservative & \\
\hline \multicolumn{5}{|c|}{ Fiscal Ideology ${ }^{e}$} \\
\hline \multicolumn{5}{|l|}{ Obesity-related issues } \\
\hline Obesity & $20(23.8)$ & $22(26.2)$ & $42(50.0)$ & $0.6(.75)$ \\
\hline Increasing traffic & $22(27.5)$ & $19(23.8)$ & $39(48.8)$ & $1.3(.53)$ \\
\hline Poorly planned development/sprawl & $21(36.8)$ & $12(21.1)$ & $24(42.1)$ & $9.9(.007)$ \\
\hline Poor nutrition & $19(34.5)$ & $19(34.5)$ & $17(30.9)$ & $17.6(<.001)$ \\
\hline Access to healthy groceries & $19(33.3)$ & $19(37.2)$ & $15(29.4)$ & $19.0(<.001)$ \\
\hline Pedestrian safety & $13(31.7)$ & $11(26.8)$ & $17(41.5)$ & $3.0(.22)$ \\
\hline Lack of pedestrian walkways & $13(31.7)$ & $14(34.1)$ & $14(34.1)$ & $7.2(.03)$ \\
\hline Lack of recreational activities & $4(19.0)$ & 7 (33.3) & $10(47.6)$ & $1.3(.53)$ \\
\hline \multicolumn{5}{|l|}{ Other health issues } \\
\hline Drug abuse & $26(23.9)$ & $27(24.8)$ & $56(51.4)$ & $0.4(.82)$ \\
\hline Access to health care & $21(36.8)$ & $16(28.1)$ & $20(35.1)$ & $14.2(.001)$ \\
\hline Climate change & $21(37.5)$ & $19(33.9)$ & $16(28.6)$ & $25.8(<.001)$ \\
\hline Tobacco & $12(22.6)$ & $17(32.1)$ & $24(45.3)$ & $3.4(.18)$ \\
\hline Pandemic influenza & 7 (17.5) & $12(30.0)$ & $21(52.5)$ & $2.0(.36)$ \\
\hline \multicolumn{5}{|l|}{ Social issues } \\
\hline Crime & $17(23.9)$ & $19(26.8)$ & $35(49.3)$ & $0.7(.69)$ \\
\hline Quality of public education & $22(36.1)$ & $16(26.2)$ & $23(37.7)$ & $13.6(.001)$ \\
\hline Homelessness & $22(36.1)$ & $19(31.1)$ & $20(32.8)$ & $19.1(<.001)$ \\
\hline \multicolumn{5}{|l|}{ Economic issues } \\
\hline Lack of good jobs & $25(26.3)$ & $23(24.2)$ & $47(49.5)$ & $1.5(.46)$ \\
\hline High taxes & $16(17.4)$ & $23(25.0)$ & $53(57.6)$ & $11.5(.003)$ \\
\hline Poverty & $28(32.6)$ & $23(26.7)$ & $35(40.7)$ & $17.7(<.001)$ \\
\hline Cost of living & $19(22.4)$ & $25(29.4)$ & $41(48.2)$ & $4.8(.09)$ \\
\hline Lack of affordable housing & 26 (32.9) & $21(26.6)$ & $32(40.5)$ & $14.5(.001)$ \\
\hline \multicolumn{5}{|l|}{ Government issues } \\
\hline Ethics in government & $18(26.9)$ & $13(19.4)$ & $36(53.7)$ & $2.0(.35)$ \\
\hline Government response to natural disasters & $7(30.4)$ & $5(26.1)$ & $10(43.5)$ & $0.9(.64)$ \\
\hline
\end{tabular}

${ }^{a}$ Respondents were asked to indicate their political ideology for social issues and fiscal issues (conservative, moderate, liberal).

${ }^{\mathrm{b}}$ We surveyed all elected officials at the state level (ie, senators and representatives) and all health directors at the municipal level in Connecticut. Response rates were $40.7 \%$ ( 74 of 182) among state elected officials and $62.7 \%$ (47 of 75 ) among municipal health directors.

${ }^{\mathrm{c}}$ Not all respondents answered all questions. Percentages are based on the number of respondents who answered question. Row percentages may not add to 100 because of rounding.

${ }^{d}$ For social ideology among elected officials and health directors who answered question $(n=116), 29$ self-reported as liberal, 39 as moderate, and 48 as conservative.

${ }^{e}$ For fiscal ideology among elected officials and health directors who answered question $(n=116), 60$ self-reported as liberal, 28 as moderate, and 28 as conservative.

The opinions expressed by authors contributing to this journal do not necessarily reflect the opinions of the U.S. Department of Health and Human Services, the Public Health Service, the Centers for Disease Control and Prevention, or the authors' affiliated institutions. 